\title{
Sex-Specific Physical Activity Patterns Differentiate Weight Loss Maintainers From Regainers: The MedWeight Study
}

\author{
Dimitrios Poulimeneas, Maria I. Maraki, Eleni Karfopoulou, Yannis Koutras, Stavrie Chrysostomou, \\ Costas A. Anastasiou, Stavros A. Kavouras, and Mary Yannakoulia
}

\begin{abstract}
Background: Although plenty of evidence indicates that weight loss maintainers are highly physically active, studies focusing on the sex-specific differences in activity levels between maintainers and regainers are scarce. The authors aimed to investigate sex-specific differences in activity patterns in a cohort of Mediterranean maintainers and regainers. Methods: Sample includes 756 participants of the MedWeight registry (60.5\% women), aged 18-65 years, who lost $\geq 10 \%$ of their initial weight, and either maintained their loss for $\geq 12$ months or regained it. Participants completed a series of questionnaires, including demographics and weight history. Activity levels were evaluated with the International Physical Activity Questionnaire-short version. Results: Maintainers of both sexes were, in total, more active than their same-sex regainers. When specific activities were considered, women maintainers spent more time walking than regainers $\left(P_{\text {adjusted }}=.02\right)$, whereas men maintainers spent more time in vigorous activities $\left(P_{\text {adjusted }}=.001\right)$ and walking than regainers $\left(P_{\text {adjusted }}=.001\right)$. Modest increments in activity of sex-relevant intensity were associated with increased odds for maintenance. Conclusions: Maintainers attained a more active lifestyle than their same-sex regainers, involving more walking for both sexes and more vigorous activities for men. The detected differences, according to activity intensity, support that activity patterns associated with successful weight loss are distinguishable between sexes.
\end{abstract}

Keywords: weight loss maintenance, weight regain, obesity

Recent guidelines strongly recommend high levels of physical activity for retaining weight loss and mitigating weight regain. ${ }^{1,2}$ Existing evidence suggests that successful postdieters more or less abide by this guidance: maintainers exercise for 30 to 60 minutes per day ${ }^{3,4}$ and engage in demanding activities (like intense aerobic exercises $){ }^{5}$ whereas regainers adopt a less active lifestyle. ${ }^{6-9}$ Furthermore, high, or even very high, levels of habitual activity are commonly reported by weight control registries participants in the United States and Europe. ${ }^{10-12}$

Besides the total physical activity levels, the components of the activity have not been well investigated. As an example, the physical activity patterns of maintainers in the National Weight Control Registry largely vary ${ }^{10}$; while vigorous exercises account for one-third of the weekly energy expenditure of maintainers, high interindividual variation was recorded, and $25 \%$ of the participants reported maintenance of weight loss with limited energy expenditure. ${ }^{13}$ At the same time, the effect of the sex may be important. Results of the few relevant studies indicate that activity patterns and levels differ between men and women maintainers. Men are more active than women, favoring more vigorous exercises, whereas women prefer exercises of moderate intensity. ${ }^{10,12}$ However, direct comparisons of the activity patterns of maintainers with their same-sex regainers are lacking. From a public health perspective, a relevant analysis could provide insight for sex-specific

Poulimeneas, Maraki, Karfopoulou, Anastasiou, and Yannakoulia are with the Department of Nutrition and Dietetics, Harokopio University of Athens, Athens, Kallithea, Greece. Maraki also is with the Section of Sport Medicine and Biology of Exercise, School of Physical Education and Sport Science, National and Kapodistrian University of Athens, Zografou, Athens, Greece. Koutras and Chrysostomou are with the School of Sciences, European University of Cyprus, Nicosia. Cyprus. Kavouras is with the Hydration Science Lab, Arizona State University, Phoenix, AZ, USA. Yannakoulia (myiannak@hua.gr) is corresponding author. activity targets in weight loss maintenance. Toward this end, we aimed to investigate possible sex differences in activity patterns between maintainers and regainers in a large European cohort of postdieters living in Greece and Cyprus.

\section{Methods}

\section{Study Design and Population}

The MedWeight study is a registry of weight loss maintainers and regainers, aiming to investigate lifestyle factors and behaviors that contribute to weight loss maintenance. We recruited participants through local and media advertising, using the study's website (http://medweight.hua.gr). Details of the MedWeight study design have been previously published. ${ }^{14}$ In the present analysis, the sample was enriched with Greek-speaking Cypriot residents. Eligible volunteers were men and women aged 18-65 years old, reporting a lifetime maximum body mass index $(\mathrm{BMI}) \geq 25 \mathrm{~kg} / \mathrm{m}^{2}$, and an intentional weight loss of $\geq 10 \%$ of their maximum weight at least 12 months prior to enrollment. Women who were currently pregnant were excluded. According to their current weight, individuals were categorized as maintainers, for reporting maintenance of $\geq 10 \%$ of initial weight loss (ie, current weight $\leq 90 \%$ of maximum weight), or regainers, for attaining a current weight $\geq 95 \%$ of their maximum body weight. To avoid overlapping between groups, those who had a current weight of $90 \%$ to $95 \%$ of their maximum weight were excluded. Sampling herein included 756 individuals (457 women and 299 men) who enrolled in the MedWeight study in Greece $(n=574)$ and Cyprus $(n=182)$, from 12/2012 to 03/2019, and had complete demographic, lifestyle, and physical activity data. Maintenance status, age, and sex distribution were similar between Greek and Cypriot participants. The ethics committee of Harokopio University, Greece, approved 
the study protocol, and all participants provided electronic informed consent.

\section{Demographics and Weight History}

Eligible volunteers were asked to report marital status (single, married/cohabiting, divorced, widowed, then coded for married/ cohabitating or not), occupational status (employed or not), and years of education. Height, current weight, maximum nonpregnancy weight ever reached, and maximum weight loss achieved were selfreported. For maintainers, only time maintaining a weight $\leq 90 \%$ of their initial weight was recorded, and the amount of weight loss they maintained (as \% of maximum weight) was computed.

\section{Physical Activity Assessment}

The short version of the International Physical Activity Questionnaire (IPAQ) validated for the Greek population ${ }^{15}$ was used to evaluate participants' physical activity, that is, weekly sessions (lasting over $10 \mathrm{~min}$ ) of vigorous, moderate activities and walking, and the time spent during these sessions. Participants were also asked to report time they spend being sedentary (in hours/working day). Brief examples for activity categories include intense aerobic exercises, lifting heavy weights, and strenuous gardening for vigorous activities; exercises of moderate intensity included moderate aerobic exercises, lifting light weights, playing tennis, etc. Walking included time spent on foot for all purposes (recreational, transport, for exercise, etc). We classified participants' physical activity levels according to the IPAQ Research Committee classification guidelines as low, moderate, or high. ${ }^{16}$ All questions regarding physical activity referred to the last week, before entering the study.

\section{Statistical Analysis}

Normality of data was graphically explored using Q-Q plots. We presented normally distributed continuous variables as mean (SD), nonnormally distributed values as medians (Q1 and Q3), and categorical variables as frequencies (in percentage). We evaluated differences between maintenance status in participants' characteristics using independent $t$ test or Mann-Whitney rank tests, and chi-square tests for categorical variables. Differences between maintainers and regainers were tested by general linear models for continuous variables and logistic regression models for categorical variables (maintenance status was the dependent variable; results were expressed as odds ratio [95\% confidence interval]). Two models were employed: unadjusted (model 1) and adjusted for age, marital status, and current BMI (model 2). Current BMI was used as a covariate, on the basis that the majority of the maintainers of our sample still attained excess BMI, a known perceived burden for participation in physical activity. ${ }^{17}$ Based on the findings of Catenacci et $\mathrm{al}^{10}$ and Santos et al, ${ }^{12}$ supporting that greater physical activity levels correlate to the magnitude of the weight loss individuals maintain, we performed a subanalysis in maintainers only. For this analysis, we performed sex-specific linear regression (percentage loss maintained was the dependent variable, results were expressed as correlation coefficient, $P$ value), with the adjustments described earlier. Statistical significance was set at 5\%.

\section{Results}

Participants' characteristics, according to weight maintenance status, are presented in Table 1. Maintainers reported maintenance of $22 \%$ weight loss (women, 22.6\% [9.9\%]; men, 22.1\% [9.6\%]) for a median period of $\sim 3$ years (women, $2.8[1.6,5.5]$; men 2.7 $[1.6,5.1])$. In both sexes, maintainers were younger, their current weight and BMI were lower, and their initial weight loss was greater, whereas a lower percentage of maintainers were married/ cohabiting compared with regainers $(P<.05$ for all comparisons).

Women maintainers, compared with regainers, were more physically active (by on average 140 total activity minutes per week, $P<.001)$, and differences were observed across almost all IPAQ domains (Table 2). However, after adjustment for age, marital status, and current BMI, only specific activity habits remained significant. Although they had similar weekly walking sessions with regainers, maintainers spent more time during these sessions (by $12 \mathrm{~min}, P_{\text {adjusted }}=.03$ ) and more time per week for walking (by $50 \mathrm{~min}, P_{\text {adjusted }}=.02$ ). For every 10 -minute increment of weekly walking, or weekly total activity, we observed $1 \%$ higher odds for weight loss maintenance, respectively (Table 3).

Table 1 Participants' Characteristics by Maintenance Status and Sex

\begin{tabular}{|c|c|c|c|c|c|c|}
\hline & \multicolumn{3}{|c|}{ Women $(n=457)$} & \multicolumn{3}{|c|}{ Men $(n=299)$} \\
\hline & $\begin{array}{c}\text { Maintainers } \\
(n=312)\end{array}$ & $\begin{array}{c}\text { Regainers } \\
(n=145)\end{array}$ & $\boldsymbol{P}$ & $\begin{array}{c}\text { Maintainers } \\
(n=205)\end{array}$ & $\begin{array}{c}\text { Regainers } \\
(n=94)\end{array}$ & $\boldsymbol{P}$ \\
\hline Age, y & $33.0(11.0)$ & $37.3(12.1)$ & $<.001$ & $31.8(9.8)$ & $35.2(11.5)$ & .01 \\
\hline Education years & $15.4(3.5)$ & $15.1(3.9)$ & .40 & $15.7(2.9)$ & $15.1(3.3)$ & .16 \\
\hline Employment status (\% employed) & 88.6 & 84.6 & .24 & 90.1 & 92.6 & .50 \\
\hline Marital status (\% married/cohabitating) & 28.1 & 46.9 & $<.001$ & 24.1 & 41.5 & .002 \\
\hline Current weight, $\mathrm{kg}$ & $69.6(13.8)$ & $84.2(16.7)$ & $<.001$ & $85.7(13.0)$ & $103.8(18.4)$ & $<.001$ \\
\hline Current BMI, $\mathrm{kg} / \mathrm{m}^{2}$ & $25.5(4.9)$ & $31.0(5.4)$ & $<.001$ & $26.8(3.8)$ & $32.5(5.3)$ & $<.001$ \\
\hline Maximum weight, $\mathrm{kg}$ & $91.5(22.2)$ & $87.0(17.4)$ & .03 & $111.9(23.7)$ & $107.2(19.2)$ & .07 \\
\hline Maximum BMI, $\mathrm{kg} / \mathrm{m}^{2}$ & $33.4(7.5)$ & $32.0(5.6)$ & .05 & $35.0(7.1)$ & $33.6(5.4)$ & .06 \\
\hline Initial weight loss, $\%$ & $27.3(10.3)$ & $18.3(6.2)$ & $<.001$ & $26.8(10.0)$ & $17.2(7.1)$ & $<.001$ \\
\hline Weight loss maintained, \% & $22.6(9.9)$ & - & - & $22.1(9.6)$ & - & - \\
\hline Maintaining years & $2.8(1.6,5.5)$ & - & - & $2.7(1.6,5.1)$ & - & - \\
\hline
\end{tabular}

Abbreviation: BMI, body mass index. Note: Values are presented as mean (SD), median (Q1 and Q3), or frequencies. $P$ values were obtained with independent $t$ tests, Mann-Whitney rank test, or chi-square test, exploring differences in the recorded parameters between weight loss maintainers and regainers of the same sex. Statistically significant results are denoted in bold (all $P<.05)$ 
In men, maintainers, compared with regainers, reported significantly more weekly activity sessions of all intensities $\left(P_{\text {adjusted }}\right.$ $<.05$ ) and more time in walking or in vigorous activities (minutes per session and weekly, $P_{\text {adjusted }}<.05$ for all comparisons) (Table 2). As a result, men maintainers were largely more totally active than regainers (by $280 \mathrm{~min} / \mathrm{wk}, P_{\text {adjusted }}<.001$ ). Being highly active (against low) was associated with 5-fold increased odds of weight loss maintenance (odds ratio $=5.12$ [2.41-10.89]), whereas every 10-minute increment in vigorous activities, walking, or in total activities was associated with $1 \%$ to $3 \%$ higher odds of weight loss maintenance (Table 3).

Finally, we performed a subanalysis in maintainers only, and we found that, in women, total activity minutes per week were associated with the percentage of weight loss that they maintain (unadjusted model: Beta $=0.152, P=.01$; adjusted model: Beta $=$ $\left.0.129, P_{\text {adjusted }}=.03\right)$. For men, no similar significant association was revealed.

\section{Discussion}

Our results support previous findings that high levels of physical activity is a prevailing behavior of individuals who maintained a significant part of their weight loss ${ }^{10-12}$; we further report sexspecific activity patterns that differentiate maintainers from regainers. In specific, women and men maintainers spent more time in walking than regainers, and, in addition, men allocated more time in vigorous activities compared with their same-sex regainers. This active lifestyle during the maintenance period may counterbalance the physiological alterations occurring after weight loss, related to energy expenditure adaptations and decreased satiety. ${ }^{18,19}$

Regarding men, we found maintainers to be largely more active than regainers, with the greater differences observed in vigorous activities. Men maintainers participated in more vigorous activity sessions per week (by 1.4 sessions) that lasted 27 minutes longer than the respective activity of regainers. High engagement in

Table 2 Sedentary and Physical Activity Patterns, by Maintenance Status and Sex

\begin{tabular}{|c|c|c|c|c|c|c|c|c|}
\hline & \multicolumn{4}{|c|}{ Women $(n=457)$} & \multicolumn{4}{|c|}{ Men $(n=299)$} \\
\hline & $\begin{array}{l}\text { Maintainers } \\
(n=312)\end{array}$ & $\begin{array}{c}\text { Regainers } \\
(n=145)\end{array}$ & $P^{a}$ & $P^{\mathbf{b}}$ & $\begin{array}{l}\text { Maintainers } \\
(n=205)\end{array}$ & $\begin{array}{c}\text { Regainers } \\
(n=94)\end{array}$ & $P^{a}$ & $P^{\mathrm{b}}$ \\
\hline Moderate exercise, $\mathrm{d} / \mathrm{wk}$ & $2.2(2.2)$ & $1.8(2.0)$ & .08 & .45 & $2.6(2.3)$ & $2.0(2.0)$ & .03 & .04 \\
\hline Moderate exercise, $\min / \mathrm{d}$ & $35.3(42.2)$ & $26.8(36.1)$ & .04 & .07 & $47.7(53.1)$ & $38.4(45.0)$ & .14 & .22 \\
\hline Moderate exercise, $\min / \mathrm{wk}$ & $60.0(0.0,150.0)$ & $40.0(0.0,120.0)$ & .04 & .21 & $80.0(0.0,240.0)$ & $60.0(0.0,125.5)$ & .07 & .15 \\
\hline Walking, d/wk & $4.8(2.3)$ & $4.3(2.5)$ & .03 & .59 & $4.8(2.4)$ & $3.7(2.5)$ & $<.001$ & .002 \\
\hline Walking, $\min / \mathrm{d}$ & $48.5(45.4)$ & $36.6(39.4)$ & .01 & .03 & $54.3(50.2)$ & $40.1(42.8)$ & .02 & .03 \\
\hline Walking, min/wk & $170(60.0,350.0)$ & $120.0(35.0,210.0)$ & $<.001$ & .02 & $150.0(70.0,390.0)$ & $100.0(30.0,210.0)$ & $<.001$ & .001 \\
\hline Vigorous exercise, $\mathrm{d} / \mathrm{wk}$ & $1.8(1.9)$ & $1.2(1.6)$ & .001 & .09 & $2.8(2.1)$ & $1.4(1.8)$ & $<.001$ & $<.001$ \\
\hline Vigorous exercise, $\mathrm{min} / \mathrm{d}$ & $38.4(44.6)$ & $31.4(44.1)$ & .12 & .63 & $64.4(56.3)$ & $37.9(52.3)$ & $<.001$ & .002 \\
\hline Vigorous exercise, $\mathrm{min} / \mathrm{wk}$ & $128.1(181.5)$ & $85.7(141.0)$ & .01 & .24 & $255.6(290.6)$ & $113.5(196.5)$ & $<.001$ & .001 \\
\hline Total activity, min/wk & $370.0(192.5,647.5)$ & $230.0(125.0,455.0)$ & $<.001$ & .03 & $520.0(260.0,1055.0)$ & $240.0(120.0,487.5)$ & $<.001$ & $<.001$ \\
\hline Sitting, h/working day & $7.6(5.6)$ & $7.4(5.0)$ & .75 & .25 & $7.1(5.2)$ & $7.8(5.6)$ & .30 & .86 \\
\hline Physical activity level, ${ }^{16} \%$ & & & .002 & .10 & & & $<.001$ & $<.001$ \\
\hline Low & 22.4 & 34.5 & & & 15.1 & 39.4 & & \\
\hline Moderate & 39.4 & 40.0 & & & 23.9 & 33.0 & & \\
\hline High & 38.1 & 25.5 & & & 61.0 & 27.7 & & \\
\hline
\end{tabular}

Note: Values are presented as mean (SD), median (Q1 and Q3), or frequencies. $P$ values were obtained with univariate general linear models or logistic regression, exploring differences in recorded parameters by maintenance status. Statistically significant results are denoted in bold (all $P<.05$ ). Models: ${ }^{\mathrm{a} u n a d j u s t e d ;}{ }^{\mathrm{b}}$ adjusted for marital status, age, and body mass index.

Table 3 Logistic Regression Models, Exploring the Relationship Between Increments in Physical Activity Components and Maintenance Status

\begin{tabular}{|c|c|c|c|c|}
\hline & \multicolumn{2}{|c|}{ Women $(n=457)$} & \multicolumn{2}{|c|}{ Men $(n=299)$} \\
\hline & $\begin{array}{l}\text { Unadjusted } \\
\text { model }\end{array}$ & $\begin{array}{l}\text { Adjusted } \\
\text { model }^{\mathrm{a}}\end{array}$ & Unadjusted & $\begin{array}{l}\text { Adjusted } \\
\text { model }^{\mathrm{a}}\end{array}$ \\
\hline Weekly vigorous activity (per $10 \mathrm{~min}$ increments) & $1.02(1.00-1.03)$ & $1.01(0.99-1.03)$ & $1.03(1.01-1.04)$ & $1.03(1.01-1.04)$ \\
\hline Weekly moderate activity (per $10 \mathrm{~min}$ increments) & $1.01(1.00-1.03)$ & $1.01(0.99-1.02)$ & $1.01(0.99-1.02)$ & $1.01(0.99-1.02)$ \\
\hline Weekly walking (per 10 min increments) & $1.01(1.00-1.02)$ & $1.01(1.00-1.02)$ & $1.01(1.00-1.02)$ & $1.01(1.00-1.02)$ \\
\hline Weekly total activities (per 10 min increments) & $1.01(1.00-1.01)$ & $1.01(1.00-1.01)$ & $1.01(1.00-1.02)$ & $1.01(1.00-1.01)$ \\
\hline $\begin{array}{l}\text { International Physical Activity } \\
\text { Questionnaire high physical activity (against low) }\end{array}$ & $2.30(1.37-3.85)$ & $1.65(0.92-2.98)$ & $5.74(3.03-10.85)$ & $5.12(2.41-10.89)$ \\
\hline
\end{tabular}

Note: Values are presented as odds ratio (95\% confidence intervals). Statistically significant $(P<.05)$ results are denoted in bold.

${ }^{a}$ Adjusted for age, marital status, and current body mass index. 
vigorous exercises is a known behavior of men, either maintainers ${ }^{10}$ or regardless of weight control. ${ }^{20}$ This may reflect the common motives that drive men to structured exercise, which are personal enjoyment ${ }^{21}$ and competition purposes ${ }^{22}$; it could also be that maintainers have overcome the barriers that overweight individuals perceive against physical activity participation. ${ }^{17}$ Men maintainers also walked more than regainers, ${ }^{10}$ both in sessions per week and activity duration. In total, men maintainers reported a generally active lifestyle that incorporates time walking, as well as more energy-demanding activities. Recent research suggests that adoption of an active lifestyle, namely being less sedentary and spending more time in light-intensity activities, in addition to higher intensity ones, is supportive of weight loss maintenance. ${ }^{8}$ Our results are also in line with findings from the Review Of Men and Obesity (ROMEO) project, proposing that men's weight loss is best maintained with increased activity. ${ }^{23}$ Altogether, the findings above may suggest that men drastically alter their lifestyle and become highly adherent to current guidance on physical activity to succeed in maintaining their weight loss.

For women, the picture was somewhat different. Although trends toward differences in all IPAQ domains were apparent, after adjustment for a set of covariates, women maintainers were, in total, more active than regainers, with profound differences in walking, in terms of duration. However, no differences were detected in activity duration in moderate or vigorous exercises, although literature suggests that moderate activities are the activity of choice of women, with ${ }^{10}$ or without ${ }^{20}$ a history of weight loss. Nevertheless, women exercise for stress release, ${ }^{24}$ thus, we hypothesize that women maintainers focus on spending more time being active, regardless of activity intensity. ${ }^{25,26} \mathrm{We}$ have previously reported that the dietary intake of women maintainers is not different from that of regainers, which implies that women adopt unique techniques of weight control that may not be easily described by distinct patterns. ${ }^{27}$ It may also be that these techniques extend to energy expenditure for women as well, suggesting that women maintainers do not drastically change their lifestyle to achieve maintenance, but find ways to adopt changes in their established routine.

Relevant to the relationship between physical activity and the percentage of weight loss that individuals maintain, we found that the total MET-minutes per week correlate to the magnitude of weight loss that women maintain. Previous findings from the United States and the Portuguese weight control registries also support that the amount of weight loss maintained positively correlates to physical activity levels, yet irrespective of sex. ${ }^{10,12}$ As this was not true for the men of our sample, we hypothesize that such an association was masked by the men maintainers' already high physical activity.

The present study has both strengths and limitations. We report findings from the largest European weight control registry. In addition, involving regainers in our sample allowed for direct comparisons of physical activity habits with maintainers of the same sex. On the other hand, the observational nature of the study reveals association but not causality. Moreover, physical activity was evaluated by a self-reported questionnaire, known to provide modest associations with objective measures of PA. ${ }^{28}$ However, self-reported questionnaires are the instrument of choice in large weight management studies ${ }^{29}$ and the IPAQ is the most widely used one, presenting high reliability and validity. ${ }^{15,30}$

In conclusion, men and women maintainers attained a more active lifestyle than their same-sex regainers, which involved more walking for both sexes and more vigorous activities for men. Our results indicate that activity profiles across maintenance status do not follow a 1-size-fits-all pattern, but they are different in men and women. Health professionals should elaborate on our findings, advising weight loss maintainers to adopt an active lifestyle and participate in structured exercises of sex-tailored intensity. Future research should include interventions exploring the possible role of various types of physical activities according to sex, in an effort to provide more robust data toward personalized exercise prescription for weight loss maintenance.

\section{Acknowledgments}

The MedWeight study was initialy funded by the Coca-Cola Foundation (2012-2015, KA 221). Dimitrios Poulimeneas received funding from the Greek State Scholarship Foundation (MIS 5000432). The authors have no competing interests to declare.

\section{References}

1. Jensen MD, Ryan DH, Apovian CM, et al. 2013 AHA/ACC/TOS guideline for the management of overweight and obesity in adults: a report of the American College of Cardiology/American Heart Association task force on practice guidelines and the obesity society. $J \mathrm{Am}$ Coll Cardiol. 2014;63(25, pt B):2985-3023. PubMed ID: 24239920 doi:10.1016/j.jacc.2013.11.004

2. Donnelly JE, Blair SN, Jakicic JM, Manore MM, Rankin JW, Smith BK. American College of Sports Medicine Position Stand: appropriate physical activity intervention strategies for weight loss and prevention of weight regain for adults. Med Sci Sports Exerc. 2009;41(2):459471. PubMed ID: 19127177 doi:10.1249/MSS.0b013e3181949333

3. Befort CA, Stewart EE, Smith BK, Gibson CA, Sullivan DK, Donnelly JE. Weight maintenance, behaviors and barriers among previous participants of a university-based weight control program. Int J Obes. 2008;32(3):519-526. doi:10.1038/sj.ijo.0803769

4. Kruger J, Blanck HM, Gillespie C. Dietary and physical activity behaviors among adults successful at weight loss maintenance. Int $J$ Behav Nutr Phys Act. 2006;3:17. PubMed ID: 16854220 doi:10. 1186/1479-5868-3-17

5. McGuire MT, Wing RR, Klem ML, Hill JO. Behavioral strategies of individuals who have maintained long-term weight losses. Obes Res. 1999;7(4):334-341. PubMed ID: 10440589 doi:10.1002/j.15508528.1999.tb00416.x

6. Cox TL, Malpede CZ, Desmond RA, et al. Physical activity patterns during weight maintenance following a low-energy density dietary intervention. Obesity. 2007;15(5):1226-1232. doi:10.1038/oby. 2007.144

7. Phelan S, Wyatt HR, Hill JO, Wing RR. Are the eating and exercise habits of successful weight losers changing? Obesity. 2006;14(4): 710-716. doi:10.1038/oby.2006.81

8. Ostendorf DM, Lyden K, Pan Z, et al. Objectively measured physical activity and sedentary behavior in successful weight loss maintainers. Obesity. 2018;26(1):53-60. doi:10.1002/oby.22052

9. Unick JL, Gaussoin SA, Hill JO, et al. Objectively assessed physical activity and weight loss maintenance among individuals enrolled in a lifestyle intervention. Obesity. 2017;25(11):1903-1909. doi:10.1002/ oby. 21971

10. Catenacci VA, Ogden LG, Stuht J, et al. Physical activity patterns in the National Weight Control Registry. Obesity. 2008;16(1):153-161. doi:10.1038/oby.2007.6

11. Soini S, Mustajoki P, Eriksson JG. Lifestyle-related factors associated with successful weight loss. Ann Med. 2015;47(2):88-93. PubMed ID: 25751374 doi:10.3109/07853890.2015.1004358 
12. Santos I, Vieira PN, Silva MN, Sardinha LB, Teixeira PJ. Weight control behaviors of highly successful weight loss maintainers: the Portuguese Weight Control Registry. J Behav Med. 2017;40(2):366-371. PubMed ID: 27586133 doi:10.1007/s10865016-9786-y

13. Catenacci VA, Odgen L, Phelan S, et al. Dietary habits and weight maintenance success in high versus low exercisers in the National Weight Control Registry. J Phys Act Health. 2014;11(8):1540-1548. PubMed ID: 24385447 doi:10.1123/jpah.2012-0250

14. Karfopoulou EA, Anastasiou CA, Hill JO, Yannakoulia M. The MedWeight study: design and preliminary results. Med J Nutrition Metab. 2014;7:201-210. doi:10.3233/MNM-140022

15. Papathanasiou G, Georgoudis G, Papandreou M, et al. Reliability measures of the short International Physical Activity Questionnaire (IPAQ) in Greek young adults. Hellenic J Cardiol. 2009;50(4):283294. PubMed ID: 19622498

16. International Physical Activity Questionnaire (IPAQ) Group. Guidelines for data processing and analysis of the International Physical Activity Questionnaire (IPAQ)—Short and long forms. 2005. http:// www.ipaq.ki.se. Accessed 16/10/2018.

17. McIntosh T, Hunter DJ, Royce S. Barriers to physical activity in obese adults: a rapid evidence assessment. J Res Nurs. 2016;21(4): 271-287. doi:10.1177/1744987116647762

18. Polidori D, Sanghvi A, Seeley RJ, Hall KD. How strongly does appetite counter weight loss? Quantification of the feedback control of human energy intake. Obesity. 2016;24(11):2289-2295. doi:10. 1002/oby. 21653

19. Anastasiou CA, Karfopoulou E, Yannakoulia M. Weight regaining: from statistics and behaviors to physiology and metabolism. Metabolism. 2015;64(11):1395-1407. PubMed ID: 26362728 doi:10.1016/ j.metabol.2015.08.006

20. Mielgo-Ayuso J, Aparicio-Ugarriza R, Castillo A, et al. Physical activity patterns of the Spanish population are mostly determined by sex and age: findings in the ANIBES study. PLoS One. 2016;11(2):e0149969. PubMed ID: 26914609 doi:10.1371/journal. pone.0149969

21. Craft BB, Carroll HA, Lustyk MK. Gender differences in exercise habits and quality of life reports: assessing the moderating effects of reasons for exercise. Int J Lib Arts Soc Sci. 2014;2(5):65-76. PubMed ID: 27668243

22. Zervou F, Stavrou NAM, Koehn S, Zounhia K, Psychountaki M. Motives for exercise participation: the role of individual and psychological characteristics. Cogent Psychol. 2017;4(1):1345141. doi:10. 1080/23311908.2017.1345141

23. Robertson C, Avenell A, Stewart F, et al. Clinical effectiveness of weight loss and weight maintenance interventions for men: a systematic review of men-only randomized controlled trials (The ROMEO Project). Am J Mens Health. 2017;11(4):1096-1123. PubMed ID: 26130729 doi:10.1177/1557988315587550

24. Asztalos M, Wijndaele K, De Bourdeaudhuij I, et al. Sport participation and stress among women and men. Psychol Sport Exerc. 2012;13(4):466-483. doi:10.1016/j.psychsport.2012.01.003

25. Jakicic JM, Marcus BH, Gallagher KI, Napolitano M, Lang W. Effect of exercise duration and intensity on weight loss in overweight, sedentary women: a randomized trial. JAMA. 2003;290(10):13231330. PubMed ID: 12966123 doi:10.1001/jama.290.10.1323

26. Jakicic JM, Marcus BH, Lang W, Janney C. Effect of exercise on 24-month weight loss maintenance in overweight women. Arch Intern Med. 2008;168(14):1550-1559. PubMed ID: 18663167 doi:10.1001/archinte.168.14.1550

27. Karfopoulou E, Brikou D, Mamalaki E, et al. Dietary patterns in weight loss maintenance: results from the MedWeight study. Eur $J$ Nutr. 2017;56(3):991-1002. PubMed ID: 26744302 doi:10.1007/ s00394-015-1147-z

28. Lee PH, Macfarlane DJ, Lam TH, Stewart SM. Validity of the International Physical Activity Questionnaire Short Form (IPAQSF): a systematic review. Int J Behav Nutr Phys Act. 2011;8:115. PubMed ID: 22018588 doi:10.1186/1479-5868-8-115

29. Swift DL, McGee JE, Earnest CP, Carlisle E, Nygard M, Johannsen NM. The effects of exercise and physical activity on weight loss and maintenance. Prog Cardiovasc Dis. 2018;61(2):206-213. PubMed ID: 30003901 doi:10.1016/j.pcad.2018.07.014

30. van Poppel MN, Chinapaw MJ, Mokkink LB, van Mechelen W, Terwee CB. Physical activity questionnaires for adults: a systematic review of measurement properties. Sports Med. 2010;40(7):565-600. PubMed ID: 20545381 doi:10.2165/11531930-000000000-00000 